J O U R N A L OF THE ROYAL SOCIETY OF MEDICINE Volume 96 December 2003

\title{
Diagnosis of abdominal tuberculosis: the importance of laparoscopy
}

\author{
S Rai MS FRCS W M Thomas MD FRCS
}

J R Soc Med 2003;96:586-588

\section{SUMMARY}

Abdominal tuberculosis (TB) tends to present with non-specific features and can be hard to diagnose. In the University Hospitals of Leicester, which serve a large immigrant population, 36 patients had this diagnosis between 1995 and 2001. We examined their records to identify features, including history, clinical presentation, investigations and diagnostic procedures, that might help with diagnosis of future cases.

32 of the patients were of Asian origin, predominantly from the Indian subcontinent. The most common presenting complaints were abdominal pain and weight loss. On clinical examination the findings were non-specific. Only 2 patients were found to have concurrent pulmonary TB. The most consistent laboratory finding (>90\%) was a low haemoglobin with a raised C-reactive protein. The tuberculin test (Mantoux) was positive in only 7 patients (22\%), and Ziehl-Neelsen staining of ascitic fluid was negative in all 11 patients in whom it was examined. An ultrasound scan of the abdomen revealed findings consistent with TB in 9/28 patients and a CT scan was helpful in 6/11. Laparoscopy, although usually performed as a last resort, proved the most effective investigation, yielding the diagnosis in $23(92 \%)$ of the 25 patients in whom it was performed.

In patients with the relevant background and clinical history, laparoscopy is the investigation of choice.

\section{INTRODUCTION}

Abdominal tuberculosis (TB) is uncommon in Europe and America but is encountered with increasing frequency by hospitals that serve growing immigrant populations. The clinical presentation tends to be non-specific, with abdominal pains and general complaints, ${ }^{1}$ and the differential diagnosis will often include inflammatory bowel disease, malignancy or some other infection. ${ }^{2}$ Prompt diagnosis allows an early start to anti-TB therapy, with advantages for the patient and savings to the health system. We therefore examined the records of patients treated in Leicester to identify clinical features and investigative methods that might help with diagnosis of future cases.

\section{PATIENTS AND METHODS}

A total of 36 patients with documented diagnosis of abdominal TB were identified with the help of the medical records departments of the University Hospitals of Leicester. These patients had presented between 1995

Department of General Surgery, Leicester General Hospital, Gwendolen Road, Leicester LE5 4PW, UK

Correspondence to: Mr Sajal Rai, 27 Hambledon Drive, Wollaton, Nottingham NG8 1LG, UK and 2001. The clinical records were then analysed for details of history, clinical signs, investigations and diagnostic procedures.

\section{RESULTS}

24 patients were male, 12 female, mean age 43 years (range 27-85). 32 were of Asian origin, 3 European and 1 AfroCaribbean.

\section{Presenting features}

Abdominal pain and pronounced weight loss were the predominant presenting complaints, followed by loss of appetite, nausea, vomiting or diarrhoea (Table 1). Just over half the patients also reported fever and night sweats. The mean duration of the presenting complaint was about 18 weeks (range 1 week to 2 years). Only 11 patients gave a relevant history of TB, 2 of whom were receiving treatment for pulmonary $\mathrm{TB}$ at the time. A further 9 reported possible contact with $\mathrm{TB}$ in the past. 28 patients were immigrants from the Indian subcontinent, 5 were immigrants from Africa, and 1 each originated from Greece, Malaysia and the UK. Of 23 patients who had been abroad since immigration to the UK, 7 had travelled in the past year, mainly to the Indian subcontinent and Africa. 


\section{Clinical features}

Generalized abdominal tenderness was the most common clinical finding but 3 had no abdominal signs at all. 14 patients were pyrexial, 8 had clinical evidence of ascites and 4 had a suggestion of an abdominal mass. Only 1 patient presented with clinical evidence of bowel obstruction.

The possibility of abdominal TB was noted at presentation in 20 patients. Intra-abdominal malignancy (10), inflammatory bowel disease (4), hepatitis, chronic pancreatitis, peptic ulcer, gastrointestinal bleed and anorexia nervosa were some of the other possibilities considered in the differential diagnosis.

\section{Investigations}

A low haemoglobin and a raised C-reactive protein (CRP) was the most consistent finding $(>90 \%)$. Chest X-ray signs were seen in 10 patients but were specific for pulmonary $\mathrm{TB}$ in only 2. Abdominal X-ray signs were detected in only 5 patients (none specific for TB). Liver function tests and white cell count were of no positive diagnostic significance. A Mantoux (tuberculin) test suggestive of $\mathrm{TB}$ was positive in only $22 \%$ of the 32 patients in whom it was performed. An ultrasound scan of the abdomen was performed in 28 patients, with findings suggestive of TB in 9 of these patients (fibrinous strands in ascitic fluid, localized ascites, calcified lymph nodes). 11 others were found to have ascites but no specific features. A CT scan of the abdomen, done in 11 patients, revealed findings consistent with abdominal TB in 6 (adenopathy predominantly in the retroperitoneal and mesenteric compartments, splenomegaly, ascites, ileocaecal mass). Staining of the ascitic fluid for acid-fast bacilli (ZiehlNeelsen) was performed in 11 cases and was negative in all. Specimens of sputum, urine and pleural fluid likewise gave negative results, and Mycobacterium tuberculosis was seen in only two of the tissue specimens obtained laparoscopically or under imaging guidance. Laparoscopy was performed in 25 of the 36 patients and was diagnostic in 23 (92\%). Of the remaining two laparoscopies, one was unsuccessful

Table 1 Presenting complaints in $\mathbf{3 6}$ patients

\begin{tabular}{ll}
\hline Presenting complaint & $\begin{array}{l}\text { No. of } \\
\text { patients (\%) }\end{array}$ \\
\hline Abdominal pain & $31(88)$ \\
Weight loss & $30(87)$ \\
Fever/night sweats & $20(55)$ \\
Loss of appetite & $25(69)$ \\
Bowel disturbance (nausea/diarrhoea) & $25(69)$ \\
Other (cough, weakness, rash, abnormal liver & $8(22)$ \\
$\quad$ function tests) & \\
\hline
\end{tabular}

because adhesions prevented creation of a pneumoperitoneum and the other was reported as normal. In the latter case a subsequent CT scan of the abdomen revealed retroperitoneal lymph nodes that on biopsy were found to be tuberculous. Of the 23 patients with positive laparoscopies, all but one had the diagnosis confirmed by laparoscopic biopsy of intra-abdominal lymph nodes or omental/peritoneal tuberculous nodules. In the remaining patient the diagnosis was established on visual findings alone since biopsy of a serosal nodule was deemed too risky. The investigation was usually performed as a last resort, in one case 145 days after presentation. In 9 of the 11 patients who did not have a laparoscopy, we judged that this investigation would have yielded an earlier diagnosis or avoided the need for laparotomy.

\section{DISCUSSION}

Abdominal TB should be considered in the differential diagnosis for patients who originate from or have travelled recently to countries where $\mathrm{TB}$ is endemic, and who present with non-specific abdominal complaints and weight loss over a long period. ${ }^{3}$ The findings of the present study confirm earlier reports on the difficulties of diagnosis including non-specific presenting features, unhelpful laboratory tests, negative results with tuberculin skin tests and Ziehl-Neelsen staining and false-negative ultrasound and CT scans. ${ }^{3-6}$ Others have found CT scan of the abdomen, used commonly as a follow-on from ultrasound, only marginally more specific for abdominal TB than ultrasound.7,8 Our findings also support previous work on the value of laparoscopy, the most specific diagnostic test for abdominal $\mathrm{TB},{ }^{9,10}$ with its advantage of histological confirmation. ${ }^{11}$ Unfortunately this investigation still tends to be used as a last resort, ${ }^{12,13}$ and our series was no exception. In former times its function was served by laparotomy, ${ }^{14,15}$ and a reluctance to intervene might then have been more reasonable. With the growing availability of experienced operators, the morbidity of laparoscopy is much less of an issue. Our findings strengthen the evidence $^{16-18}$ that, in patients with a relevant background and clinical history, laparoscopy is the investigation of choice.

\section{REFERENCES}

1 Teh LB, Ng HS, Ho MS, Ong YY. The varied manifestations of abdominal tuberculosis. Ann Acad Med Singapore 1987;16:488-94

2 Apaydin B, Paksoy M, Bilir M, Zengin K. Value of diagnostic laparoscopy in tuberculosis peritonitis. Eur J Surg 1999;165:158-63

3 Wells AD, Northover JM, Howard ER. Abdominal tuberculosis: still a problem today. $J$ R Soc Med 1986;79:149-53

4 Wilairatana P, Wilairatana S, Lekhyananda S, Charoenlarp P. Does laparoscopy have a limited role in diagnosis of fibroadhesive tuberculous peritonitis? Southeast Asian J Trop Med Publ Health 1993;24:762-5

5 al Quorain AA, Satti MB, al Gindan YM, al Ghassab GA, al Freihi HM. Tuberculous peritonitis: the value of laparoscopy. HepatoGastroenterology 1991;38:37-40 
6 Badaoui E, Berney T, Kaiser L, Mentha G, Morel P. Surgical presentation of abdominal tuberculosis: a protean disease. HepatoGastroenterology 2000;47:751-5

7 Jadvar H, Mindelzun RE, Olcott EW, Levitt DB. Still the great mimicker: abdominal tuberculosis. Am J Roentgenol 1997;168: 1455-60

8 Haddad FS, Ghossain A, Sawaya E, Nelson AR. Abdominal tuberculosis. Dis Colon Rectum 1987;30:724-35

9 Rodriguez de Lope C, San Miguel Joglar G, Pons Romero F. Laparoscopic diagnosis of tuberculous ascites. Endoscopy 1982;14:178-9

10 Semenovski AV, Barinov VS, Kochorova MN. Laparoscopy in the complex diagnosis of abdominal and genital tuberculosis. Problemy Tuberkuleza 1999;3:36-9

11 Wolfe JH, Behn AR, Jackson BT. Tuberculous peritonitis and role of diagnostic laparoscopy. Lancet 1979;i:852-3
12 Inadomi JM, Kapur S, Kinkhabwala M, Cello JP. The laparoscopic evaluation of ascites. Gastrointest Endosc Clin N Am 2001;11:79-91

13 Bhargava DK, Shriniwas, Chopra P, Nijhawan S, Dasarathy S. Peritoneal tuberculosis: laparoscopic patterns and its diagnostic accuracy. Am J Gastroenterol 1992;87:109-12

14 Lambrianides AL, Ackroyd N, Shorey BA. Abdominal tuberculosis. Br J Surg 1980;67:887-9

15 Tacyilcliz I, Akgun Y, Boylu S. Abdominal tuberculosis: diagnosis and surgical therapy in 139 cases. Br J Surg 1997;84:92

16 Tison C, de Kerviler B, Kahn X, Joubert M, Le Borgne J. Videolaparoscopic diagnosis and follow-up of a peritoneal tuberculosis. Ann Chirurg 2000; 125:776-8

17 McLaughlin S, Jones T, Pitcher M, Evans P. Laparoscopic diagnosis of abdominal tuberculosis. Aust NZ J Surg 1998;68:599-601

18 Kasia JM, Verspyck E, Le Boudec G, Struder C. Peritoneal tuberculosis: value of laparoscopy. J Gynécol Obstét Biol Reprod 1997;26:367-73 